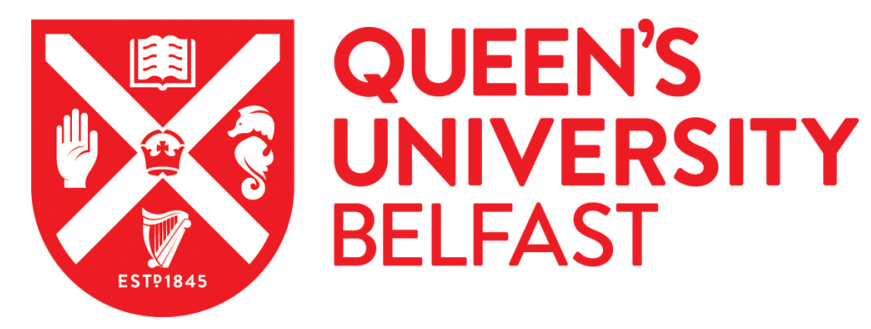

\title{
Public Sector Reforms: Changing Contours on an NPM Landscape
}

Hyndman, N., \& Liguori, M. (2016). Public Sector Reforms: Changing Contours on an NPM Landscape. Financial Accountability \& Management, 32(1), 5-32. https://doi.org/10.1111/faam.12078

\author{
Published in: \\ Financial Accountability \& Management
}

\section{Document Version:}

Peer reviewed version

\section{Queen's University Belfast - Research Portal:}

Link to publication record in Queen's University Belfast Research Portal

\begin{abstract}
Publisher rights
(c) 2016 Wiley

This is the peer reviewed version of the following article: Hyndman, N. and Liguori, M. (2016), Public Sector Reforms: Changing Contours on an NPM Landscape. Financial Accountability \& Management, 32: 5-32, which has been published in final form at

http://onlinelibrary.wiley.com/doi/10.1111/faam.12078/abstract. This article may be used for non-commercial purposes in accordance with

Wiley Terms and Conditions for Self-Archiving.

\section{General rights}

Copyright for the publications made accessible via the Queen's University Belfast Research Portal is retained by the author(s) and / or other copyright owners and it is a condition of accessing these publications that users recognise and abide by the legal requirements associated with these rights.
\end{abstract}

\section{Take down policy}

The Research Portal is Queen's institutional repository that provides access to Queen's research output. Every effort has been made to ensure that content in the Research Portal does not infringe any person's rights, or applicable UK laws. If you discover content in the Research Portal that you believe breaches copyright or violates any law, please contact openaccess@qub.ac.uk. 


\title{
Public Sector Reforms: Changing Contours on an NPM Landscape
}

\section{NOEL HYNDMAN AND MARIANNUNZIATA LIGUORI*}

\begin{abstract}
Previous studies suggest that public sector accounting has moved from Public Administration (PA) to New Public Management (NPM) ideas and, more recently, towards a New Public Governance (NPG) approach. These systems are presented as mutually exclusive and competing. Focusing on accounting changes in the UK central government, this paper explores whether movements towards NPG ideas can be identified at the level of political debate. No evidence is found that NPM is a transitory state. Rather, the findings demonstrate that political debate continues to utilise predominantly NPM arguments, with the three systems viewed as containing complementary, rather than competing, schemes.
\end{abstract}

Keywords: accounting reforms, New Public Management, New Public Governance, Central Government

Running title: Public Sector Reforms: Changing Contours

*The authors are both from the Queen's University Management School, Queen's University, Belfast, UK.

Address for correspondence: Noel Hyndman, Queen's University Management School, Riddle Hall, 185 Stranmillis Road, Belfast, UK, BT9 5EE.

e-mail: n.hyndman@qub.ac.uk 


\section{INTRODUCTION}

Public administration has the propensity to experience 'identity crises' (Waldo, 1968). Previous studies suggest that over the decades there has been a continuous movement in public administration systems from traditional Public Administration (PA) ideas to managerial ones, later labelled as New Public Management (NPM) reforms, and more recently, towards a more participative approach utilising partnerships and networks, referred to as New Public Governance (NPG). Each of these systems is associated with its own accounting, budgeting and performance measurement tools and techniques. The three systems are often presented as mutually exclusive and competing (Rhodes, 1997; Pollitt and Bouckaert, 2011; and Prestoff et al., 2012). However, the claim that there has been a progressive movement along a continuum from PA to NPM, and ultimately to NPG, has also been contested (Pollitt, 2007; and Lapsley, 2008). While there have been a number of studies looking at the implementation of accounting reforms associated with these systems (Christensen and Lægreid, 2007; and Connolly and Hyndman, 2006), little is known about the political debate preceding these reforms and on whether this follows the direction some of the literature would suggest.

The objective of this study is to explore whether a convincing movement towards NPG ideas can be identified at the level of political debate; and to what extent the ideas embedded within PA, NPM and NPG systems show themselves in the political discussions regarding public sector accounting and budgeting reforms. Has the emphasis of political debate on these three systems changed over the last eighteen years? To what extent does this suggest a movement along a continuum from PA towards NPG, with NPM merely a transitory state on the journey? Has a movement along a continuum (if any) led to a replacement of previous ideas? The paper focuses on the accounting, budgeting and performance measurement changes that took place in the United Kingdom (UK) central government from the 1990s and, through a document analysis, explores the extent to which the language used in the documents mirrors any of the old 
and new public administration reform vocabularies. In particular, we investigate, over time, the relative use, and change in use, of the language related to PA, NPM and NPG.

The paper aims to contribute to the on-going discussion on public sector reforms and their evolution towards an increasingly NPG-like approach (Osborne, 2006 and 2010; Pollitt, 2007; and Lapsley, 2008). The findings suggest that the political debate regarding accounting reforms in official UK political documents has predominantly, but not exclusively, utilised NPM arguments, with little evidence of a 'NPG-era' even in the later periods. In particular, while PA, NPM and NPG are often, although not always (Pollitt and Bouckaert, 2011), presented in the literature as mutually exclusive, competing schemes, the results of this research suggest that in political debate they are viewed as complementary, with decisions taken that result in layering, rather than replacement, of systems. On the basis of the analysis, there is very limited evidence to support the claim that NPM is a transitory state in the evolution from a regime of traditional PA to NPG. The paper is organised as follows: the following section reviews existing literature on the three public administration systems (namely PA, NPM and NPG); then the methods and the document analysis are presented; finally, after a section discussing the emerging results, the conclusions present final remarks and identify further research avenues.

\section{PUBLIC SECTOR REFORMS AND IDEAS OVER THE LAST EIGHTEEN YEARS}

Since the 1970s many governments have engaged in reform processes aimed at bringing business concepts, techniques and values into the public sector (Pollitt and Bouckaert, 2011). This movement has been termed NPM and often resulted in major shifts in accounting, budgeting and performance measurement systems as a basis for better management and more appropriate accountability (Connolly and Hyndman, 2006). As a consequence, it is argued that there has been (Hood, 1995), and indeed should be (Osborne and Gaebler, 1992), a significant and progressive movement away from traditional bureaucratic PA systems, in favour of NPM-type management and accounting tools and ideas inspired by the private sector. International comparisons of 
NPM-style reforms across a number of countries indicate that these reforms are being implemented at a quicker pace and more enthusiastically in some countries compared to others (Hood, 1995; and Flynn and Strehl, 1996). For example, Hood (1995) produced an analysis outlining the degree of NPM intensity in various countries and their national governments' political orientation at that time. He argued that political orientation (and right-wing governments) could not explain the degree of implementation of NPM ideas. An alternative view, indicated by Flynn and Strehl (1996), suggests that NPM ideas require an ideological commitment that is likely to be stronger among conservatives than socialists or social democrats. However, there are exceptions to this, as Bach and Bordogna (2011) also showed that in a group of core 'NPM enthusiasts' (Anglophone countries characterised by a majoritarian political system, an individualist pro-market culture and strong governance systems), NPM-inspired reforms have been more consistently pursued, regardless of the political hue of the government. The UK has been proposed as one of these 'enthusiasts'.

More recently, an increasing body of literature has identified, under the banner of NPG, a new focus on governance systems to steer public services and actors (Osborne, 2010; and Prestoff et al., 2012). In what could be viewed as a reaction to the fragmentation of the public sector through the adoption of NPM ideas, NPG focuses on the need for networks, rather than hierarchies and markets, as a means of making governments more effective and legitimate (Osborne, 2010; and Pollitt and Bouckaert, 2011). According to these studies, NPM is dead (Dunleavy at al., 2006) and we have now entered an era of 'governance without government', as a mode of de-bureaucratised, hybrid societal steering (Klijn, 2008; and Lynn, 2010).

\section{Traditional Public Administration}

PA systems, the ideas of which have dominated public service delivery regimes since the late nineteenth century to the early 1980s, have at their heart the rule of law. Here, politics and administration are clearly separated (with the former prevailing on the latter) and the hegemony 
of professionals is dominant with respect to public service delivery (Hood, 1991). From a historical perspective, traditional PA could itself be regarded as a major reform movement. Instead of public administration being carried out by amateurs often appointed on the basis of connection, the task of administering public organisations was professionalised, and efficiency and appointment on merit became key. PA is most commonly linked with the ideas of Weber (1947) and is characterised by: an administration under the formal control of the political leadership, fixed spheres of competence, defined hierarchies, full-time, permanent and neutral officials, specialisation and expertise as the basis for action, clear distinction between the public and private roles of officials, and management by the application of developed rules (Politt and Bouckaert, 2011).

With respect to accounting, the budget often plays a central role as a basis for the political negotiation and the (generally incremental) allocation of resources among different political programmes and purposes, with the budget seen as a political act which translates political goals into appropriations of financial resources (Wildavsky, 1964; and Liguori et al., 2012). Attention is focused on the legitimacy of the budget process and, ex-post, on the comparison between actual and authorised expenditure (ter Bogt, 2003), with accounting primarily intended to ensure compliance and curtail spending. Strict rules, standardised procedures and a focus on cash are at the heart of the accounting system.

\section{New Public Management reforms}

While there was a massive expansion in the role of the state between 1945 and the early 1970s, driven in the main by rising expectations and the demand for greater equality, from the 1970 s onwards serious questioning of such expansion began to emerge. Possible reasons for this are financial distress, social changes, globalisation, increased competition, and changing perceptions of the state (for a discussion of these see Hyndman and McGeough, 2008). Such questioning forced governments to consider the role of the state, the manner in which public services were 
delivered to citizens and the accountability of the public sector. Consequently, the management of public sectors in a number of western countries has changed with, collectively, these changes being referred to as NPM.

Hood (1991) suggested that NPM is a convenient, though a rather loose, term that is a shorthand for a set of broadly similar administrative doctrines that dominated the reform agenda in the public sector in many OECD countries. NPM reforms typically have evolved around six dimensions: privatisation, marketisation, decentralisation, output orientation, quality systems and intensity of implementation (Pollitt and Summa, 1997). This is evidenced in the UK public sector by, among other things, the increasing adoption of private-sector managerial techniques, the development of market mechanisms and the break-up of large units of government into smaller quasi-autonomous units. These adjustments have been viewed as ways of improving accountability by public sector bodies, and decision making within public sector bodies, and have drawn heavily on new accounting, budgeting and performance measurement systems (Hyndman et al., 2007; and Lapsley, 2008). In the field of accounting, many governments that have embraced NPM ideas have also adopted the accruals basis of accounting (as opposed to a cash basis), private sector style financial statements (vs. budget out-turn reports relating to cash spent), decentralised budgets (vs. strong central control of budgets), flexibility in budget carry forward (in place of strict annuality) and a focus on performance reporting relating spend to outputs and achievements (in place of a focus on the control of inputs). Objectives, targets and identification of the cost of individual services to permit rational choice also tend to feature prominently in accounting systems supporting NPM reforms.

A number of authors have suggested that in many reform experiences, these new ideas and tools, rather than replace existing systems with better systems, have a tendency to perpetrate old logics and behaviours, often making public organisations more formalised and bureaucratic than previously (Dunleavy and Hood, 1994; and Pollitt and Bouckaert, 2011). It has been argued that the initial enthusiasm relating to NPM reforms has declined over time, so that NPM is now 
in its middle age. This is as a consequence of reformers ignoring or downplaying its paradoxes and side effects, and being overconfident in the general efficacy of the remedies they initially advocated (Hood and Peters, 2004). Some authors have even claimed that NPM is dead, although others contest this (Dunleavy at al., 2006; Pollitt, 2007; Lapsley, 2008; and Osborne, 2010).

\section{New Public Governance reforms}

In the last two decades a plethora of ideas relating to 'governance' have gradually emerged to challenge both traditional PA and NPM reforms (Rhodes, 1997; and Osborne, 2006 and 2010). Governance is argued to entail the steering of society through networks and partnerships between governments, businesses and other forms of civil society (Pollitt and Bouckaert, 2011). Osborne (2010) opines that NPM, rather than being the final destination of a reform process, has (p.1) 'been a transitory state in the evolution' from a regime of traditional PA to NPG. He contends that both traditional PA and NPM reforms fail (p.5) 'to capture the complex reality of the design, delivery and management of public services in the twenty-first century' and calls for a more sophisticated understanding of public policy adoption, implementation and public service delivery.

It is argued (Osborne, 2006) that NPG reforms (as compared with NPM systems): have their theoretical roots in sociology and network theory (rather than rational management and public choice); assume a plural and pluralist state (rather than a disaggregated state); focus on inter-organisational governance (rather than intra-organisational management); emphasise service processes and outcomes (rather than service inputs and outputs); relate to external non-public organisational partners with ongoing preferred-supplier relationships (rather than market relationships); use trust and relational contracts as governance mechanisms (rather than market mechanisms); and place their faith in neo-corporatist values (rather than the efficacy of competition and the market place). These ideas, however, have also been accompanied by a 
partial rediscovery of rule and legal principles, where the state, with its own rules, methods and culture, fundamentally remains the key actor (Hupe et al., 2000).

The concept of governance, as part of the NPG changes, is not an alternative to government, but represents a wider and more inclusive system of ideas, based on partnerships among government, business and citizens' associations. The emphasis is shifted towards networks, partnerships and negotiated voluntary cooperation, rather than competition or hierarchies. NPG reforms move away from an emphasis on traditional hierarchical forms of organisation and focus on more devolved and participative (task-specific) controls (Rhodes, 1997). They build on ideas relating to more efficient and flexible service delivery procedures (concepts first highlighted in the NPM approach) to answer the needs of an increasingly diverse citizenry and acknowledge an increased complexity of public sector accountability mechanisms as a response to increasing numbers of stakeholders and ambiguous objectives (Rhodes, 1997; and Christensen and Lægreid, 2011). With such reforms, the focus of accounting techniques moves more and more towards the reassurance of social efficacy and effectiveness (highlighting the ensuring of citizens' satisfaction and attention to outcomes), as well as external accountability and transparency (European Commission, 2001). According to Ackerman (2012), accountability is meant to stimulate citizens' participation, favouring ex-ante, proactive and horizontal systems. In such systems transparency and participative endeavours come to the fore.

\section{METHOD}

This paper investigates the language and the change in the vocabularies used in relation to the three main public sector reforms identified by the literature (i.e. PA, NPM and NPG), with a particular focus on accounting, budgeting and performance measurement systems. In particular, we aim to explore, over time, whether NPG ideas and vocabularies defined a change of scene in the political debate, as recent literature would predict (Osborne, 2006 and 2010; and Ackerman, 2012). This is interpreted in the context of the changes decided in the UK central government 
during the 1990s and 2000s (here split into four consecutive periods to identify changes, if any, over time). The history of the changes was reconstructed on the basis of the relevant official reform documents, archival materials (such as published articles) and interviews with central government managers (see Table 1). The analysis of documents was facilitated using a textual analysis approach. The discursive dynamics were reconstructed on the basis of specific text genres that were included in documents that accompanied the legislative process ${ }^{1}$. These comprised a total of 45 documents (2,440 pages) including: (i) text of an enacted law in parliament's national archives; (ii) explanatory notes to the Resource Accounting and Budgeting (RAB) bill (the only relevant bill issued over the analysed period), accounting for the background and rationale of the law and its amendments; (iii) administrative reports which explored areas with some significant focus on accounting and budgeting reform (such as reports discussing how accountability might be discharged or performance measured) issued by governmental and parliamentary committees ${ }^{2}$; and (iv) transcripts of the first and the final bill discussions in both chambers of parliament (House of Commons and House of Lords) and parliamentary committee reports examining modifications to the law or existing administrative regulation.

PA, NPM and NPG have characteristic standard narratives, vocabularies, ideas, concepts and instruments (Mills, 1940) that signify adherence to its major thrusts. In order to identify the systems and reforms that the texts invoked, we developed a dictionary of such 'signature elements' or 'cues' (verbal expressions that suggest one of the core concepts that the literature proposes for each system) (Hyndman et al., 2014). The dictionary of cues used is reported in Appendix 1. For example: references to efficiency, contract, agencification or competition were used to identify commitment to the NPM reform agenda; NPG was associated with words/phrases such as networks, citizen participation, transparency or external accountability; PA was identified in relation to such cues as rule, compliance or procedure. With some of these cues, there is a degree of overlap, and it could be debated as to whether they should be related to one particular system or another. For instance, accountability and consolidation represent cues utilised by both NPM and NPG reforms. In 
these cases, previous research was reviewed to identify the extent to which the literature expressed the cue as being central to a specific system, or firstly introduced under a certain reform (see concepts such as citizen for PA or contracting-out, PPP and PFI for NPM - Hood, 1991; and Pollitt and Bouckaert, 2000 and 2011). The cue was located in the system where the strongest case was made. In addition, it should be noted that our analysis exceeds an automatic search or quantitative counting of words: the dictionary greatly aided the coding, but all documents were read by the coders in detail and it was left to the coders' interpretation whether a keyword was used to cue a particular commitment to a system or not. Data coding and analysis were supported by the software ATLAS.ti.6.

A statement can draw on a specific cue to either endorse or criticise a particular system or reform agenda. To identify this, we distinguished between 'positive/neutral' (i.e. supporting codes - PA1, NPM1 and NPG1 codes) versus 'negative' (i.e. criticising or challenging codes PA2, NPM2 and PG2) usage of the cue words within each vocabulary. In order to increase internal validity and reliability, the codebook was applied to each of the documents independently by two researchers, with all cases of disagreement reviewed and resolved by discussion. The unit of analysis was the paragraph. The weighted number of occurrences, and occurrences per page, related to the three systems (distinguishing between positive and negative cues) is shown in Tables 2 and 3.

For the analysis of the relative prevalence of each system (PA, NPM or NPG), we counted the number of occurrences of different signature cues within each paragraph ${ }^{3}$. For example, when four different NPM1 codes, supporting NPM arguments, occurred in a single paragraph, the paragraph was 'weighted' as NPM1 multiplied by four. In addition, in order to explore the extent to which cues relating to different (arguably competing) systems existed together, we explored their co-occurrence by assigning binary codes to each paragraph, indicating whether specific reform discourses were present or not. For instance: when an NPM1 code occurred four times in a paragraph together with two PA1 codes, the paragraph was 
counted once as a PA1/NPM1 co-occurrence; whereas when a PA1 code appeared in a paragraph three times with no other code, it was counted once as a PA1 alone. Finally, to identify the main specific cues in each system being used, the main keywords (i.e. words accounting for over $5 \%$ of the hits in one system in any of the four periods) were collected and analysed. The co-occurrence counts for various combinations of codes are presented in Table 4, with a snapshot of commonly used system-related keywords outlined in Table 5.

\section{CHANGES IN ACCOUNTING, BUDGETING AND PERFORMANCE MEASUREMENT}

\section{SYSTEMS: A UK PERSPECTIVE}

At the beginning of the 1990s, accounting, budgeting and performance measurement in the UK central government featured cash budgeting with strict annuality requirements, cash accounting, and limited performance measurement and performance management. During the two following decades (the 1990s and the 2000s), major changes associated with a modernisation agenda were introduced. Key features of these are presented in Table 1.

\section{Insert Table 1 here}

In the $1990 \mathrm{~s}$, as far as accounting is concerned, a major change pertained to the announcement relating to the introduction of accrual-based accounting. The arguments for using the accrual model, in place of cash accounting, gained prominence and acceptance, and a move from the cash basis was agreed for central government. This was eventually implemented in the early 2000s under the title of Resource Accounting and Budgeting (RAB). Resource accounting, which extends beyond the cash-based accounting used previously by applying accrual principles to central government department accounting, also sought to integrate objectives and targets into the accounting system (implemented in full by 2001). In addition, on the management accounting side, a subsequent move to resource budgeting, in order to make the management 
accounts align with the external accounts in central government, was made (implemented in full by 2003). The position of accrual accounting was further embedded by the decision in 1998 to produce Whole of Government Accounts (WGA) (a consolidated set of accrual financial statements for the UK public sector, consolidating around 1,500 bodies), although the first set of WGA was not produced until $2011^{4}$.

With respect to performance measurement and management, in the 1980s there had already been calls for a greater focus on such issues, which could be seen clearly in the Financial Management Initiative (HM Government, 1982). Since the 1990s, performance measurement and reporting became integral parts of the development of $\mathrm{RAB}$ and came again to the fore in the introduction of Public Service Agreements (PSAs) and Service Delivery Agreements (SDAs) in 1998. In these, central government departments were held accountable for service delivery through the targets set out in their PSAs and SDAs.

Finally, in the realm of budgeting, major changes also occurred. As alluded to above (and shown in Table 1), the move from cash budgeting to resource (accrual) budgeting was announced in the mid 1990s and was 'live' by 2003. In addition, annuality (the requirement for budget allocations to be spent by the financial year-end or be surrendered to the centre) was abolished in 1997 at central government departmental level with end-year flexibility (EYF) being permitted (allowing the carry forward of unspent resources from one year to the next). Moreover, in 1998, Treasury-led Spending Reviens were initiated to set firm and fixed spending budgets over several years for each government department rather than rely on single-period budgeting.

\section{ANALYSIS OF RESULTS: CHANGES IN A SHADE OF ... NPM}

\section{$P A, N P M$ and NPG in the UK political debate}

A synopsis of the cues linked to the three main reform waves (PA, NPM and NPG) over an eighteen-year period (1991-2008) is provided in Table 2. This shows, in absolute and percentage 
terms, the 'weighted' number of occurrences of different signature cues within each paragraph, categorised in each of the six possible codes (a negative and a positive code for each of the three systems). Table 3 shows the same counts normalised by the total number of pages in the documents for each of the periods.

Both tables give us a clear picture, where ideas supporting NPM systems, techniques and logics (identified by NPM1 codes) prevail overall with an average of 63.5\% (see Table 2) and 3.5 cues per page of document (Table 3). NPM is clearly the most represented and discussed reform system in the political debate throughout the whole period and is almost always presented in positive terms (NPM2 cues only occurring in 1.1\% of cases in eighteen years). NPM surpasses the traditional PA system, which showed an average of $24.9 \%$ positive (PA1) cues over the period (1.37 cues per page of document). However, cues relating to PA clearly persisted in the UK discussions, notwithstanding the multiple waves of managerial and accounting modernisation. The utilisation of traditional PA cues, supportive of PA ideas (PA1), increased proportionately in the 1990 s before reducing in the 2000 s.

In terms of occurrence, NPM1 arguments remained high in each of the four periods (well over $50 \%$ in each period), being at their highest in the first period (70.2\%), before decreasing in the second period to $54.3 \%$ and increasing again to over $65 \%$ in each of the last two periods. A similar oscillating pattern, at a much lower level, occurred with PA1 cues, with peaks and troughs occurring almost as mirror images of NPM1 (understandably so, as these two codes dominated the analysis over the four periods, accounting for over $85 \%$ of cues in each period).

Although the use of NPG1 cues remained relatively low throughout the entire period (averaging only $7.6 \%$ of total cues and 0.42 cues per page), it grew consistently from a minimal level in the first period $(5.5 \%)$ to a significantly higher level in the fourth period $(13.2 \%)$. It is interesting to note that there was very limited use of negative cues (PA2, NPM2 or NPG2) in the documents. Indeed, looking at each of the systems (PA, NPM and NPG), on average, over the 
four periods, these accounted for only 2.8\% (PA2), 1.1\% (NPM2) and 0.1\% (NPG2) of the total cues and were never more than $4 \%$ in any one period (Table 2).

Insert Table 2 and Table 3 here

The co-occurrence counts for the main combinations of codes (e.g. PA1/NPM1, PA1/NPG1, PA1 alone, etc.) are highlighted in Table 4 together with the percentage of the total number of paragraphs in each period (a detailed overview is presented for each of the three systems separately - PA, NPM and NPG). The less occurring combinations of codes are collapsed into the 'Other' column. Considering the PA system first (the upper third of Table 4), it can be seen that PA arguments (which were present in 2,767 paragraphs in the eighteen-year period) were mostly presented together with NPM ones, and overwhelmingly in a positive manner. The most usual code combinations were PA1/NPM1 (48.4\% over the entire eighteenyear period) and PA1 alone (38.9\% of paragraphs), although the prevalence of one of these over the other fluctuated between periods. In the period $1991-1995,53.1 \%$ of paragraphs were PA1/NPM1 compared with 37.3\% PA1 alone; in the subsequent period, PA1 alone was more widespread. No other code combinations using PA arguments were particularly frequently identified (averaging less than 5\% over the eighteen-year period) in any of the four periods.

This picture is reversed for NPM arguments (the middle third of Table 4), where it is seen that NPM arguments (which surfaced in 5,425 paragraphs in total in the entire period under consideration) most commonly appeared in positive terms and by themselves (NPM1 alone) within a paragraph, rather than being associated with any other reform system. This is true in each of the four periods. For example, in the period 1991-1995 65.7\% of paragraphs were NPM1 alone $(59.2 \%$ for the entire eighteen-year period). The next most frequent code combination was NPM1/PA1 (24.7\% of the NPM paragraphs over the eighteen years). . 
With respect to NPG arguments (the lower third of Table 4), these were present in a total of only 936 paragraphs over the eighteen-year period. On average, they appeared more frequently in a positive hue (NPG1) in combination with positive NPM1 arguments (NPG1/NPM1 accounting for 41.6\% of all NPG paragraphs during the eighteen-year period), although this was not consistent through the four periods. The other most prevalent code combinations were NPG1 alone (29.7\% of paragraphs) and NPG1/PA1/NPM1 $(14.5 \%$ of paragraphs). NPG1 alone, in particular, was the most frequently occurring code during the periods 1996-1999 (31\%) and 2004-2008 (40.3\%); although, in the latter case, it was the result of an analysis of the only 67 paragraphs available for the period.

\section{Insert Table 4 here}

To explore the use of particular, system-related (PA, NPM or NPG) words in the political debate regarding accounting, budgeting and performance measurement, an analysis of the prevalence of the specific cues used (see Appendix 1) was also undertaken. This is reflected in Table 5, which focuses on the weighted counts of the main keywords and shows an example of the extent to which the relative use of common system-related words ebbs and flows over the period considered. For presentation purposes, we define a keyword as any one of the Appendix 1 original cues that accounts for over $5 \%$ of the hits in any one system (PA, NPM or NPG) in any one of the four periods. Given this, the total percentages of the keywords in any one system shown in Table 5 are less than 100\% in any period, and the individual system-related counts are greater than the sum of the total for the keywords. In line with the previous analysis contained in Table 2, the total overall counts for PA, NPM and NPG were very different (9,973 PA cues, 18,367 NPM cues and 2,525 NPG cues), and therefore care must be taken in interpreting the percentage information. Similarly, the much higher number of words analysed in the middle two periods (1996-1999 and 2000-2003) reflects the higher numbers of documents in these periods. 
With respect to PA, cash/commitment, expenditure and spending were by far the most prevalent words, particularly in the first three periods, where together, in each of the periods, they accounted for over $60 \%$ of all PA cues (Table 5). This fell to $56.3 \%$ in the last period (20042008), as citizen, a PA cue hardly used in other periods, emerged more strongly. In the case of NPM, the keywords resources, audit/auditing and cost were the most prevalent, together accounting for over 50\% of the NPM words in the entire period (although this was much lower in the 20042008 period at 19.7\%). NPM performance-related cues (such as objective, performance and target) together accounted for only $6.9 \%$ of the NPM cues in the entire period, but a much higher proportion in the later periods $(10.9 \%$ of NPM words in period three $-2000-2003$, and $19.9 \%$ in period four - 2004-2008). With NPG, by far the most common cues used over the entire period were accountability and consolidation/consolidated (words that are also borderline with NPM ideas) that together accounted for $52.1 \%$ of the overall NPG words (Table 5). Of note is the fact that integration/integrated, network and governance emerged as keywords in period four (2004-2008), although they were hardly present at all in earlier periods. Governance, in particular, emerged strongly, accounting for $34.8 \%$ of NPG hits in the last period.

\section{Insert Table 5 bere}

The following subsections explore the four periods under analysis in more detail, paying particular attention to the parallel between the proposed changes and the ideas and arguments actually being discussed in each period.

The early $\mathrm{R} A B$ years: 1991-1995

The domination of NPM-related topics in the political debate regarding accounting, budgeting and performance measurement particularly coincided in the mid-1990s with the discussions around the Green (HM Treasury, 1994) and the White (HM Treasury, 1995) papers (both finally 
converging into the RAB bill in 2000). As a consequence of these RAB-related proposals, and the discussion surrounding them, in the first period under consideration (1991-1995), over 70\% of the cues in the documents relating to accounting utilised the language associated with NPM in a positive manner (NPM1) (Table 2). When we look at Table 5 and the way specific keywords appear, in this period NPM cues such as cost (16.7\% of the NPM keywords) and especially resources in accrual terms (30.9\% of NPM keywords) came to the fore. This is unsurprising given the widespread discussion of $\mathrm{RAB}$ in the political debate. At this time, language positively associated with PA ideas (PA1) was present, but much more muted $(20.2 \%$ of the total cues, Table 2), while positive NPG cues (NPG1) were almost absent (5.5\% of the total cues).

If we look at the co-occurrences across the different reform vocabularies during this period, arguments in favour of PA were mostly presented together with NPM ones (Table 4). Between 1991 and 1995, 53.1\% of the times it was present, PA1 co-occurred together with positive NPM arguments, and only $37.3 \%$ of the times by itself. This picture is reversed for NPM, which largely appeared by itself, rather than associated with any of the other systems. This co-occurrence of PA1/NPM1 is particularly reflected in the concurrent use of cost and expense cues (used in an NPM1 sense) with the PA1 cues of cash and expenditure in discussions and debates on $\mathrm{RAB}$ (Table 5). This suggests a complementarity of arguments, rather than a competition between system-related arguments. Furthermore, between 1991 and 1995, although in $33 \%$ of the paragraphs where it was present NPG appeared by itself in a positive mode (NPG1), it was more often accompanied by arguments supporting NPM-type changes (NPG1/NPM1 - 50.5\%). Ideas related to all three systems (PA, NPM and NPG) were rarely present together.

The emergence of PSAs, SDAs, EYF and WGA: 1996-1999

The second half of the 1990s saw an increase in all the system codes (Table 2), consistent with the increased number of documents and pages of accounting-related political debate in the 
period (Table 3). While positive NPM cues (NPM1) continued to be most pervasive, and increased in numbers, they accounted for a lower proportion of total cues than in the earlier period (54.3\% compared with $70.2 \%$ in $1991-1995$, see Table 2$)$, suggesting no movement from PA to NPM ideas at this time in the political debate. The number and proportion of both PA and NPG codes rose.

In this period, performance measurement and reporting continued to be identified and discussed as integral parts of the development of RAB. Additionally, it was further embedded by the development of PSAs and SDAs in 1998 (Table 1). In 1997, annuality was abolished at central government departmental level with EYF being permitted (see Table 1$)^{5}$. The use of accrual accounting was further embedded by the decision in 1998 to undertake a scoping study with the objective of producing WGA. In the same year, the Treasury introduced a more structured Spending Review process.

These changes covered old and new areas of central government accounting and thus led to an increase in the use of terms supporting all the three systems (Table 5): the old PA, reinvigorated by the focus on expenditure and cash, never forgotten, and again emphasised in the Spending Review; the newly introduced NPM (with performance-related cues like objective, performance and target increasing in use, as well as cost, audit and resources); and the incubating NPG (with growing use of accountability, transparency and, related to WGA, consolidation cues). This is also the period where the most was written in relation to accounting, budgeting and performance measurement reforms (1,083 pages, see Table 3), surpassing even the years 2000-2003 when the RAB bill was approved and published.

In this period PA, NPM and NPG were presented mainly independently (i.e. as standalones) in each paragraph (Table 4). The three systems of ideas only co-occurred marginally, with the exception of when the NPG cues were examined. NPG1 appeared together with positive NPM and PA cues in 19.7\% of the NPG paragraphs, the highest proportion over the four periods (and much higher than any three way co-occurrence when considering NPM 
and PA cues). This might suggest the rise of a new set of ideas (which would be identified later in the literature as NPG reforms). These ideas were grafted into the political debate, but could not, at this point, be recognised as a self-standing paradigm.

The $\mathrm{R} A B$ era: $2000-2003$

The move from cash budgeting to resource (accrual) budgeting announced in the mid-1990s went 'live' in 2003 (Table 1). Previously, in 2001, resource (accrual) accounting had become operational in all central government departments with performance-related Statements of Resources by Departmental Aims and Objectives as part of this RAB change. In the 2000-2003 period, the NPM and NPG occurrences increased (in terms of counts and percentage of hits). For example, positive NPM (NPM1) hits increased from 2,677 (2.47 per page; $54.3 \%$ of all hits) in 1996-1999 to 4,226 hits (4.74 per page; $68.7 \%$ of all hits) in $2000-2003$. A similar pattern was observed with positive NPG (NPG1) cues, but at much lower levels (Tables 2 and 3). At the same time, there was a clear decrease in the relative presence of PA-supporting arguments (Table 2): this is highlighted by the co-occurrences, where positive PA cues in a standalone mode (PA1 alone) were much less frequently found $(26.9 \%$ of paragraphs compared with $46 \%$ in the immediately preceding period - see Table 4). The decline of this traditional set of ideas might echo the coming into play of the managerial RAB-related reforms, a few years after them being announced. What had been seeded is now becoming more and more visible. For example, given the introduction of $\mathrm{RAB}$ during this period, the fact that keywords such as anditing (accounting for $18.7 \%$ of the NPM cues) and resources (27.7\% of the NPM cues) were pervasive in the political debate was perhaps not unexpected (Table 5).

A more definite split across the old (PA) and the new (NPM and NPG) systems is also visible in the lower co-occurrence rate of PA1, NPM1 and NPG1 together $112.8 \%$ of NPG paragraphs in this period, down from $19.7 \%$ in the previous period - Table 4) and in the substantial stability of the main terms (such as cash, expenditure and spending) used to support PA 
systems (Table 5). While the old PA world crystallises, and, being already embedded in the culture, perhaps does not require further emphasis or slogans for it to be embraced, in the new NPG realm things keep moving and the related terminology develops as the new ideas are introduced, discussed and become engrained. This is shown by its rapidly evolving vocabulary, which sees, in this period, a reduction in the use of NPG keywords such as transparency and consolidation, and the increase in use of the term accountability (Table 5).

\section{A journey towards governance? 2004-2008}

Over the last period under analysis there were fewer documents, fewer pages and fewer systemrelated hits (Tables 2 and 3). Key themes of the period were particularly embedded in the Governance in Britain Green Paper of 2007. It contained a number of proposals relating to constitutional reform, and had an overarching aim of increasing citizens' inclusion and participation in the managing of public services. The demand for enhanced forms of external accountability was also strongly addressed (Table 1). At the same time, preparation was ongoing for WGA (with the first set of WGA eventually produced in 2011).

Due to the governance issues being discussed, the preparation for the consolidated WGA to be published in the future and the ongoing debate regarding the alignment of the key RAB documents, NPM ideas remained at the fore and discussions of NPG ideas accelerated strongly in these last four years (2004-2008). For example, $65.2 \%$ of all hits related to positive NPM (NPM1) cues (slightly down from the $68.7 \%$ in the previous period, see Table 2). While NPM words previously emphasised, such as resources and audit, showed a decrease, other words such as responsibility and process became more important (Table 5). This was possibly as a consequence of the stronger search for legitimation in the context of citizens and external stakeholders, something particularly emphasised in Governance in Britain. With respect to positive NPG cues (NPG1), these increased strongly as a percentage of total system-related hits (from $8.5 \%$ to $13.2 \%$, Table 2 ), and showed the highest percentage of cues in any of the four periods. 
Further evidence of NPG's rapidly developing vocabulary is seen in Table 5, with a major expansion of the use of the NPG keywords governance, participation and integration. Moreover, the use of accountability and transparency, which had emerged strongly in previous periods, remained solid. Similar to the previous period, PA-supporting arguments (PA1) remained relatively low at $21.3 \%$ of hits (Table 2), below the average for the four periods, with the PA keyword citizen, which was almost unused in previous periods, accounting for $39.8 \%$ of PA hits (Table 5).

In terms of co-occurrence, we see a change in how NPG arguments were presented. As indicated in Table 4, the highest percentage (in total) of NPG paragraphs represented standalones (40.3\%), possibly indicating an emerging strength of the NPG ideas. However, care should be taken in interpreting this as: this was the period with the lowest number of documents and total hits, and positive NPG cues (NPG1) were still more likely to co-occur within paragraphs with positive NPM or PA cues (Table 4).

\section{DISCUSSION OF RESULTS: LOOKING BACK AT THE PAST EIGHTEEN YEARS}

Looking at the four periods as a whole (1991-2008), we see a move from cash accounting, cash budgeting and strict annuality (PA ideas) to accrual accounting (live by 2001), accrual budgeting (live by 2003) and EYF (from 1997). Similarly, the expansion and focus on performance measurement and management, and the introduction of PSAs and SDAs in 1998, are indicative of NPM themes being embedded. These adjustments were features of a rolling programme of accounting reforms associated with NPM ideas between 1991 and 2008. However, the three sets of ideas, PA, NPM and NPG, associated with different reform packages, always co-existed (although to differing extents) over the eighteen years. The contention that an autonomous NPG paradigm has emerged in the UK in the last decade, as theorised by some authors (Osborne, 2006 and 2010; Ackerman, 2012; and Prestoff et al., 2012), is not supported by the research that forms the basis of this paper. Differently, we find that in the UK, as PA has weakened (although not disappeared), NPM ideas have been consistently strong and have been augmented as NPG 
ideas have been interwoven. NPG, rather than replacing NPM, complements and is an essential part of it.

Among the three waves of reform, NPG represents the weakest and most recent. From a low commencement base in the early 1990s, it emerged more forcefully in the 2000s but, even then, the overall average occurrence of positive cues (NPG1) for the entire period (1991-2008) was by far the lowest of the three systems. Moreover, it is interesting to note that the most recurrent NPG terms in the UK central government scene actually cover aspects that previous literature has identified as borderline with NPM (Pollitt and Bouckaert, 2011). For instance, both NPG and NPM reforms can be associated with the keyword consolidation, the most recurrent NPG cue over the last eighteen years $(30.2 \%$ on average - see Table 5), and accountability (the second in terms of frequency, $21.9 \%$ on average). As indicated earlier in the paper, for analysis purposes, both consolidation and accountability were each viewed as NPG cues. Even doing this (which should 'strengthen' the NPG case), and reflecting on the consequent results, it is arguable as to whether NPG can be considered a new system of ideas in itself. The results seem to support the view that NPG is largely an adjustment of NPM reforms (Lapsley, 2008 and 2009; and Pollitt and Bouckaert, 2011).

Some writers have argued that NPM ideas are more likely to be accepted by right-leaning governments (in a UK context, a Conservative government). However, there is very little evidence to support this in the data. At the initial stage of the period covered in this study, the Conservative party was in government (up to 1997). This was followed by a more centrist (or left-leaning) New Labour government (from 1997 to 2010). Ideas supporting NPM (NPM1), however, appear just as strongly in political debates in the later periods of this study (when a New Labour government was in power) as in the earlier periods (with a Conservative government - Tables 1 and 2). Moreover, many of the NPM-related accounting changes announced in the Conservative era were pushed through vigorously in the New Labour era 
(Table 1). As Cutler (2007) and Lapsley and Midwinter (2010) argue in relation to the UK, there is clear evidence that NPM ideas were embraced enthusiastically by all governments.

Interestingly, the study also highlights the substantial co-existence of multiple (supposedly alternative) public administration approaches and ideas. A possible explanation for this finding is that the process of reform in accounting, budgeting and performance measurement techniques has been generally characterised by a layering of the different ideas that complement, rather than supplant, each other over time. This reflects a pattern where new emerging structures and ideas are super-imposed (or layered) on pre-existing ones (Liguori, 2012). This interpretation is consistent with what Pollitt and Bouckaert $(2011$, p.8) find during reform implementation, where 'the detail of public sector reform often turns out to be more like geological sedimentation, where new layers overlie but do not replace or completely wash away the previous layer'. Our case shows that, at the level of political debate, changes appear to build on each other and suggest the grafting of new ideas onto existing systems. Adopting such a philosophy negates the need for negative arguments and explains the very limited presence of negative codes (i.e. arguments criticising any of the three reform streams). This highlights a general trend, where reforms are discussed in positive terms and introduced identifying their strengths, rather than the previous systems' weaknesses. This would also explain the observed coexistence of accounting, budgeting and performance measurement systems relating to different reform waves, where both 'old' and 'new' system cues are present together.

\section{CONCLUSIONS AND FURTHER RESEARCH}

Utilising extensive document analysis, and focusing on changes in accounting, budgeting and performance measurement in the UK central government over an eighteen-year period, this paper explores the use of reform vocabularies and the degree to which a movement towards NPG ideas can be identified in the political discussions regarding public sector accounting reforms. Besides the actual content of the reform decisions, the paper examines: the extent to 
which the vocabularies used to debate possible changes are related to the vocabularies of the three public administration systems; whether the systems are seen as mutually exclusive and/or competing in political discussions; and whether there is evidence of a movement over time from PA to NPM and then to NPG.

Our research highlights very limited evidence to support Osborne's (2010) argument that NPM is a transitory state in the evolution from a regime of traditional PA to NPG. The fact that the usage of the NPG vocabulary is weak (although increasing) places doubt over whether it can yet rightly be described as a self-standing, autonomous paradigm at all. Indeed, when one considers the main NPG keywords found in the research (Table 5), by far the most widely used were accountability and consolidation. Such words, arguably, could have been located in the NPM dictionary. Moreover, when the co-occurrence of PA, NPM and NPG is considered, the code 'NPG1 alone' occurs only $29.7 \%$ of the times NPG cues are present (much lower than any other standalone code). In comparison, the combined code NPG1/NPM1 accounts for $41.6 \%$ of the times NPG occurs (Table 4), suggesting that NPG is more often associated with NPM ideas.

In contrast, the analysis provides evidence that the rhetoric regarding accounting, budgeting and performance measurement reforms has predominantly used managerial arguments, irrespective of the political stances of the government in office. Considering the occurrence of the system-related cues for each of the three systems (PA, NPM and NPG), NPM is by far the most widely used in each of the four periods (Table 2), despite different governments being in power at different times. Moreover, when this is considered in tandem with the decided changes (Table 1), it largely shows a consistency between the tendency to use NPM cues and the decisions to introduce NPM-related changes. However, some care must be exercised in interpreting the results, because truly taken-for-granted topics require no justification and therefore do not easily surface in official discourses (Green, 2004). Therefore long-standing ideas (probably emanating from the time-honoured tradition of a PA system) may not need to be included in the arguments, tending to result in an understatement of adherence to 
PA principles. This is consistent with the modest level of identification of PA occurrences, as discussed in the results.

PA, NPM and NPG are often presented in the literature as mutually exclusive, competing systems. The evidence in this study suggests that this is not the case. If it were the case, one would expect, in political debate and discussion, arguments made against one system as support for change to another system. For example, arguments in favour of an NPM change (NPM1) would be made together with an argument against PA (PA2); the argument being that NPM changes are necessary replacements for outdated PA systems. This tendency occurs very infrequently. Instead, we often find arguments in favour of one system (for example, NPM) presented in the same paragraph as arguments in support of another system (for example, PA). This implies that NPM changes are often seen as supporting established PA systems and suggests that changes are not necessarily replacements of, but rather complements to, existing systems. This reflects a pattern of new emerging ideas super-imposed (layered or sedimented) on pre-existing ones rather than new emerging ideas replacing pre-existing ones (Liguori, 2012). As Streeck and Thelen (2005) suggest, the changes that are observed today are not merely minor adaptations of what has been before, but rather, through their accumulating impacts, resulting in a major recasting of systems.

This paper contributes to the on-going debate on public sector reforms and the possible evolution towards an increasingly NPG-like approach. First, on the basis of the evidence from this research, we dispute the claim that NPM is a transitory state in the evolution from a regime of traditional PA to NPG. Instead, we concur with Lynn's (2010) view, expressed when discussing the nature of NPG as a new paradigm of public administration, opining that any paradigm which does not require changes in political institutions and systems is doomed to be just another academic fashion. In our research, we find that political debates are still strongly framed within the 'old' NPM, rather than the 'new' NPG. Why NPM ideas have been so pervasive in discussions and debates surrounding public administration is still unclear, and 
beyond the objective of this paper. After the Second World War there was a massive expansion in the role of the state across OECD countries. This was driven by rising expectations and demand for greater equality (Sanderson, 1996). However, in the last thirty years major changes have taken place in relation to the role, function and management of the public sector. From the 1970s serious doubts began to be raised about the continued expansion of the state (Bovaird and Loffler, 2009; and Flynn and Strehl, 1996). These prompted the push for public sector reforms, with some seeing them in terms of improving the performance, transparency and accountability of the public sector (Flynn and Strehl, 1996), while others in terms of a fundamental questioning of the role of the state (Sanderson, 1996).

Second, unlike the majority of studies on the topic, which focus on reform implementation and their unintended consequences, this research examines the political debate surrounding accounting-change decisions at the moment they are taken. The analysis suggests that the adoption of PA, NPM and NPG ideas is not as clear cut as some implementation studies have claimed. What we see in the UK political discussion of the past eighteen years is largely an NPM landscape, contoured with different aspects of NPM coming to the fore at different times (as particular changes are debated in the political arena) and the acknowledgement throughout that traditional PA and emerging NPG ideas also have validity. Rather than NPM ideas and tools completely replacing PA ones, we see NPM (and some NPG concepts) supplementing and complementing traditional systems. As Lynn (2012, p.119) has suggested, 'whatever may be new will be rooted in soil that is very old indeed'.

As in all studies, this research has limitations and can be augmented by further research. Firstly, our empirical focus is purely on the UK, an early and strong reform initiator. Other studies comparing across different countries, possibly with differing administrative cultures and traditions, would enrich the findings and help identify if a more or less linear trajectory exists in the move (if any) from PA to NPM and NPG systems. Secondly, the research relies almost totally on document analysis. Interviews with key actors in and around the decisions that are 
taken regarding changes to accounting systems would provide additional insights. Finally, the research has looked at what the debate was, not why the debate occurred in the way it did and what the particular influencing factors were. Additional research could broaden the scope of analysis to periods before the 1990s in order to explore the existence and interplay of NPM and NPG ideas. Moreover, further research could investigate the level of 'action' (Brunsson, 1989) and actual implementation of the discussed changes, and the role played by organisational conditions in different countries. 


\section{NOTES}

${ }^{1}$ This does not deny the relevance of other communication arenas, such as the media (Meyer and Höllerer, 2010). However, as the area of financial and budgetary accounting reforms can be assumed to be 'expert talk', we expect these documents to be representative of the relevant arguments.

${ }^{2}$ In the UK most accounting and budgeting changes do not pass through law, but rather are introduced through administrative acts.

${ }^{3}$ The total number of hits for the three systems (PA, NPM and NPG) over the four periods was 13,447.

${ }^{4}$ Although the initial 1998 timetable targeted 2006 as the first year where such accounts were to be produced, this was delayed until 2011. It has been argued that a combination of competing priorities, limited resources, the UK public sector moving to International Financial Reporting Standards (IFRS), and political and fiscal changes were largely responsible (Heald and Georgiou, 2011).

${ }^{5}$ In the face of financial pressure, the government more recently argued that the end-year flexibility (EYF) system led to accumulated surpluses that would further increase the deficit if they were spent. As a consequence, the EYF system was discontinued from 2011-2012 (House of Commons, 2011). 


\section{REFERENCES}

Ackerman, J.M. (2012), 'From Co-Production to Co-Governance', in V. Prestoff, T. Brandsen and B. Verschuere (eds.), New Public Governance, the Third Sector and Co-Production (Routledge, Oxon).

Bach, S. and L. Bordogna (2011), 'Varieties of new public management or alternative models? The reform of public service employment relations in industrialised democracies, The International Journal of Human Resource Management, Vol. 22, No. 11, pp.2281-2294.

Bovaird, T. and E. Loffler (2009), Public Management and Governance, $2^{\text {nd }}$ Ed. (Routledge, London).

Brunsson, N. (1989), The organization of hypocrisy: Talk, decisions, and actions in organizations (John Wiley \& Sons, New York).

Christensen, T. and P. Lægreid (2007), Transcending New Public Management. The transformation of public sector reform (Ashgate, Aldershot).

(2011), 'Complexity and hybrid public administration: Theoretical and empirical challenges', Public Organization Review, Vol. 11, No. 4, pp.407-23.

Connolly, C. and N. Hyndman (2006), 'The actual implementation of accruals accounting: Caveats from a case within the UK public sector', Accounting, Auditing \& Accountability Journal, Vol.19, No. 2, pp.272-290.

Cutler, T. (2007), 'A necessary complexity: history and public-management reform', History \& Policy, December, Accessed 30.12.2014 at: http://www.historyandpolicy.org/papers/policypaper-67.html

Dunleavy, P., H. Margetts, S. Bastow and J. Tinkler (2006), 'New Public Management is dead. Long live digital-era governance', Journal of Public Administration Research and Theory, Vol. 16, pp.467-94.

and C. Hood (1994), 'From old Public Administration to New Public Management', Public Money and Management, Vol. 14, No. 3, pp.9-16.

European Commission (2001), Governance in the European Union: A White Paper (European Commission, Brussels).

Flynn, N. and F. Strehl (1996), Public Sector Management in Europe (Prentice Hall, London).

Green, S.E. (2004),'A rhetorical theory of diffusion', Academy of Management Review, Vol. 29, No. 4, pp.653-69.

Heald, D. and G. Georgiou (2011), 'The macro-fiscal role of the U.K. Whole of Government Account', Abacus, Vol. 43, No. 4, pp.446-76.

HM Government (1982), Efficiency and effectiveness in the civil service (Cmnd 8616) (The Stationery Office, London).

HM Treasury (1994), Accounting for taxpayer's money: Resource accounting and budgeting in government, a consultation paper (Cmnd 2626) (The Stationery Office, London).

London).

(1995), Better accounting for taxpayer's money (Cmnd 2929) (The Stationery Office,

Hood, C. (1991), 'A Public Management for all seasons?', Public Administration, Vol. 69, No. 1, pp.3-19.

(1995), 'The 'New Public Management' in the 1980s: Variations on a theme', Accounting, Organizations and Society, Vol. 20, No. 2/3, pp.93-109. 
and G. Peters (2004), 'The Middle Aging of New Public Management: Into the Age of Paradox?', Journal of Public Administration Research and Theory, Vol. 14, No. 3, pp.267-282.

House of Commons (2011), Hansard Written Answers for 28 Feb 2011, Accessed 30.12.2014 at:

http://www.publications.parliament.uk/pa/cm201011/cmhansrd/cm110228/text/110228w0002.ht $\mathrm{m}$.

Hupe, P.L., L. Meijs and M.H. Vorthoren (2000), Hybrid Governance: The impact of the nonprofit sector in the Netherlands (Social and Cultural Planning Office, The Hague).

Hyndman, N., R. Jones and M. Pendlebury (2007), 'An exploratory study of annuality in the UK public sector: plus ça change, plus c'est la même chose?', Financial Accountability \& Management, Vol. 23, No. 2, pp.215-237.

M. Liguori, R.E. Meyer, T. Polzer, S. Rota and J. Seiwald (2014), 'The translation and sedimentation of accounting reforms. A comparison of the UK, Austrian and Italian experiences', Critical Perspective on Accounting, Vol. 25 Nos. 4/5, pp. 388-408.

and F. McGeough (2008), NPM and performance measurement: a comparative study of the public sectors in Ireland and the UK', The Irish Accounting Review, Vol. 15, No. 2, pp.5-46.

Klijn, E. (2008), 'Governance and Governance Networks in Europe: An Assessment of Ten Years of Research and the Theme', Public Management Review; Vol. 10, No. 4, pp.505-25.

Lapsley, I. (2008), 'The NPM agenda: Back to the future', Financial Accountability \& Management, Vol. 24, No. 1, pp.77-96.

(2009), 'New Public Management: The Cruellest Invention of the Human Spirit?', Abacus, Vol. 45, No.1, pp.1-21.

and A. Midwinter (2010), 'The Modernisation of the State: The Comprehensive Spending Review in the UK' (published as: 'Moderniser L'Etat: Les Aspects Financiers Des Programme Reviews Au Royaume-Uni'), Revue Francaise D Administration Publique, No.136, pp.821-35.

Liguori, M. (2012), 'Radical Change, Accounting and Public Sector Reforms: A Comparison of Italian and Canadian Municipalities', Financial Accountability \& Management, Vol. 28, No.4, pp.437-463.

, Sicilia, M. and I. Steccolini (2012), 'Some like it non-financial... politicians' and managers' views on the importance of accounting information', Public Management Review, Vol. 14, No. 7, pp.27-70.

Lynn, L.E. Jr. (2010), 'What endures? Public governance and the cycle of reform', in S.P. Osborne (ed.), The New Public Governance? Emerging perspectives on the theory and practice of Public Governance (Routledge, London and New York).

(2012), 'The Many Faces of Governance: Adaptation? Transformation? Both? Neither?' in D. Levi-Faur (ed), The Oxford Handbook of Governance (Oxford University Press, Oxford), pp. 49-64.

Meyer, R.E. and M. Höllerer (2010), 'Meaning structures in a contested issue field: A topographic map of Shareholder Value in Austria', Academy of Management Journal, Vol. 53, No. 6, pp.124162.

Mills, C.W. (1940), Situated actions and vocabularies of motive', American Sociological Review, Vol. 5, No. 6, pp.904-13. 
Osborne, D. and T. Gaebler (2002), Reinventing Government: How the Entrepreneurial Spirit is Transforming the Public Sector (Addison Wesley, Reading).

Osborne, S.P. (2006), 'The New Public Governance?', Public Management Review, Vol. 8, No. 3, pp.377-87.

(2010), 'Introduction. The (New) Public Governance: A suitable case for treatment?', in S.P. Osborne (ed.), The New Public Governance? Emerging perspectives on the theory and practice of Public Governance (Routledge, London and New York).

Pollitt, C. (2007), 'The New Public Management: An Overview of its Current Status', Administratiesi Management Public, Vol. 8, No. 1, pp.110-115.

and G. Bouckaert(2011),Public sector reform. A comparative analysis: New Public Management, Governance, and the Neo-Weberian State, 3rd ed. (Oxford University Press, Oxford).

University Press, Oxford).

(2000), Public Management Reform : A Comparative Analysis (Oxford

Pollitt, C. and H. Summa (1997), 'Trajectories of Reform: Public Management Change in Four Countries', Public Money \& Management, Vol. 17, No. 1, pp.7-18.

Prestoff, V., T. Brandsen and B. Verschuere (2012), New Public Governance, the Third Sector and CoProduction (Routledge, Oxon).

Rhodes, R. (1997), Understanding governance. Policy networks, governance, reflexivity and accountability (Open University Press, Buckingham).

Streeck, W. and K. Thelen (2005), Beyond Continuity: Institutional Change in Advanced Political Economies (Oxford University Press, Oxford).

Sanderson, I. (1996), 'Evaluation, learning and the effectiveness of public services: Towards a quality of public service model', International Journal of Public Sector Management, Vol. 9, Nos. 5/6, pp. $90-108$.

ter Bogt, H.J. (2003), 'Performance evaluation styles in governmental organizations: How do professional managers facilitate politicians' work?', Management Accounting Research, Vol. 14, No. 4, pp.311-32.

Waldo, D. (1968), The Novelist on Organization \& Administration; an Inquiry Into the Relationship Between Two Worlds (Institute of Governmental Studies, University of California, CA).

Weber, M. (1946), 'Politics as a vocation', in H.H.Gerth and C.W. Mills (eds.), From Max Weber (Oxford University Press, New York), pp.77-128.

Wildavsky, A.B. (1964), The politics of the budgetary process (Little, Brown and Co.,Boston). 


\section{TABLES}

\section{Table 1: Main features of the UK accounting, budgeting and performance measurement reforms}

\section{1-1995}

$1094-95$

- Announced that resource (accrual) accounting and budgeting to be introduced in all government departments as part of the Resource Accounting and Budgeting (RAB) changes (late 1990s - 1994 with the Green Paper, 1995 with the White Paper - dry-run and transitional exercises to bed system down).

- Announced that Statements of Resources by Departmental Aims and Objectives to be introduced in all government departments as part of the RAB changes - late 1990s dry-run and transitional exercises to bed system down.

\section{7}

\section{6-1999}

- $\quad$ End-year flexibility (EYF) introduced with respect to budget carry forward. 1998

- Treasury first published a scoping study for Whole of Government Accounts (WGA).

- Performance-focused Public Service Agreements (PSAs) and Service Delivery Agreements (SDAs) introduced as a key-aspect of a quasi-contract between the Treasury and government departments.

- Treasury-led Spending Reviews initiated to set firm and fixed spending budgets over several years for each government department.

$2000-2003$

2001

- Resource (accrual) accounting 'live' in all central government departments.

- Statements of Resources by Departmental Aims and Objectives required to be produced as part of the RAB changes in all central government departments. 2003

- $\quad$ Resource (accrual) budgeting 'live' in all central government departments 2004-2008

2007

- Government discussion paper published with the objective of facilitating better accountability of public bodies to parliament and to the public.

- Announced that financial accounting of government departments to be based on IFRS.

- Clear Line of Sight (CLOS) project commenced aimed at getting better alignment of accounting and budgeting information. 
Table 2: Reform cues in the UK political debate - a time comparison

\begin{tabular}{|c|c|c|c|c|c|c|c|}
\hline \multirow{3}{*}{$91-95$} & PA1* & PA2 & NPM1 & NPM2 & NPG1 & NPG2 & Total \\
\hline & $360^{* *}$ & 52 & 1,253 & 15 & 98 & 7 & 1,785 \\
\hline & $20.2 \%$ & $2.9 \%$ & $70.2 \%$ & $0.8 \%$ & $5.5 \%$ & $0.4 \%$ & $100 \%$ \\
\hline \multirow{3}{*}{$96-99$} & PA1 & PA2 & NPM1 & NPM2 & NPG1 & NPG2 & Total \\
\hline & 1,763 & 116 & 2,677 & 37 & 330 & 4 & 4,927 \\
\hline & $35.8 \%$ & $2.4 \%$ & $54.3 \%$ & $0.8 \%$ & $6.7 \%$ & $0.1 \%$ & $100 \%$ \\
\hline \multirow{3}{*}{ 00-03 } & PA1 & PA2 & NPM1 & NPM2 & NPG1 & NPG2 & Total \\
\hline & 1,103 & 203 & 4,226 & 95 & 521 & 4 & 6,152 \\
\hline & $17.9 \%$ & $3.3 \%$ & $68.7 \%$ & $1.5 \%$ & $8.5 \%$ & $0.1 \%$ & $100 \%$ \\
\hline \multirow{3}{*}{ 04-08 } & PA1 & PA2 & NPM1 & NPM2 & NPG1 & NPG2 & Total \\
\hline & 124 & 2 & 380 & 0 & 77 & 0 & 583 \\
\hline & $21.3 \%$ & $0.3 \%$ & $65.2 \%$ & $0.0 \%$ & $13.2 \%$ & $0.0 \%$ & $100 \%$ \\
\hline \multirow{3}{*}{$\begin{array}{c}\text { Total } \\
\text { (all periods) }\end{array}$} & PA1 & PA2 & NPM1 & NPM2 & NPG1 & NPG2 & Total \\
\hline & 3,350 & 373 & 8,536 & 147 & 1,026 & 15 & 13,447 \\
\hline & $24.9 \%$ & $2.8 \%$ & $63.5 \%$ & $1.1 \%$ & $7.6 \%$ & $0.1 \%$ & $100 \%$ \\
\hline
\end{tabular}

*supporting codes - PA1, NPM1 and NPG1 codes vs. criticising or challenging codes - PA2, NPM2 and PG2

** number of absolute counts

Table 3: Reform cues in the UK political debate - average per page

\begin{tabular}{|c|c|c|c|c|c|c|c|}
\hline & & \multicolumn{3}{|c|}{ Counts } & \multicolumn{4}{c|}{ Average per page } \\
\hline & Total Pages & PA1 $^{*}$ & NPM1 & NPG1 & PA1 norm & NPM1 norm & NPG1 norm \\
\hline $\mathbf{9 1 - 9 5}$ & 345 & 360 & 1,253 & 98 & 1.04 & 3.63 & 0.28 \\
\hline $\mathbf{9 6 - 9 9}$ & 1,083 & 1,763 & 2,677 & 330 & 1.63 & 2.47 & 0.30 \\
\hline $\mathbf{0 0 - 0 3}$ & 891 & 1,103 & 4,226 & 521 & 1.24 & 4.74 & 0.58 \\
\hline $\mathbf{0 4 - 0 8}$ & 121 & 124 & 380 & 77 & 1.02 & 3.14 & 0.64 \\
\hline $\begin{array}{c}\text { Total } \\
\text { (all periods) }\end{array}$ & 2,440 & 3,350 & 8,536 & 1,026 & 1.37 & 3.50 & 0.42 \\
\hline
\end{tabular}

${ }^{*}$ supporting codes - PA1, NPM1 and NPG1 codes 
Table 4: Reform cues and co-occurrences in the UK political debate - a time comparison

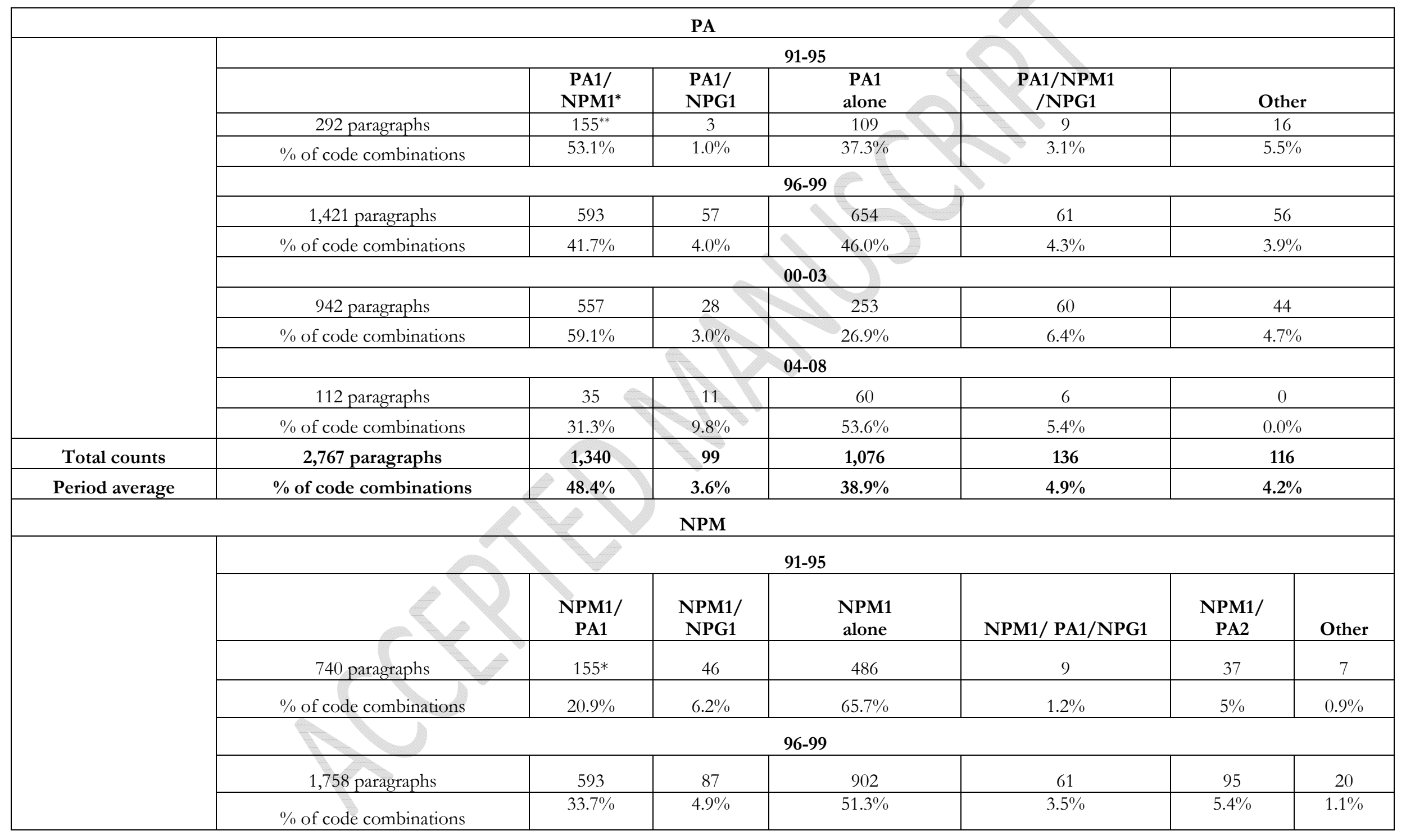




\begin{tabular}{|c|c|c|c|c|c|c|c|}
\hline & \multicolumn{7}{|c|}{ 00-03 } \\
\hline & 2,702 paragraphs & 557 & 233 & 1666 & 60 & 147 & 39 \\
\hline & $\%$ of code combinations & $20.6 \%$ & $8.6 \%$ & $61.7 \%$ & $2.2 \%$ & $5.4 \%$ & $1.4 \%$ \\
\hline & \multicolumn{7}{|c|}{ 04-08 } \\
\hline & 225paragraphs & 35 & 23 & 160 & 6 & 1 & 0 \\
\hline & $\%$ of code combinations & $15.6 \%$ & $10.2 \%$ & $71.1 \%$ & $2.7 \%$ & $0.4 \%$ & $0.0 \%$ \\
\hline Total counts & 5,425 paragraphs & 1,340 & 389 & 3,214 & 136 & 280 & 66 \\
\hline Period average & $\%$ of code combinations & $24.7 \%$ & $7.2 \%$ & $59.2 \%$ & $2.5 \%$ & $5.2 \%$ & $1.2 \%$ \\
\hline \multirow{2}{*}{\multicolumn{8}{|c|}{ NPG }} \\
\hline & & & & & & & \\
\hline & & $\begin{array}{l}\text { NPG1/ } \\
\text { NPM1 }\end{array}$ & $\begin{array}{c}\text { NPG1/ } \\
\text { PA1 }\end{array}$ & $\begin{array}{l}\text { NPG1 } \\
\text { alone }\end{array}$ & $\begin{array}{c}\text { NPG1/ } \\
\text { PA1/NPM1 }\end{array}$ & \multicolumn{2}{|c|}{ Other } \\
\hline & 91 paragraphs & $46^{*}$ & 3 & 30 & 9 & \multicolumn{2}{|c|}{3} \\
\hline & $\%$ of code combinations & $50.5 \%$ & $3.3 \%$ & $33.0 \%$ & $9.9 \%$ & \multicolumn{2}{|c|}{$3.3 \%$} \\
\hline & \multicolumn{7}{|c|}{ 96-99 } \\
\hline & 310 paragraphs & 87 & 57 & 96 & 61 & \multicolumn{2}{|c|}{9} \\
\hline & $\%$ of code combinations & $28.1 \%$ & $18.4 \%$ & $31.0 \%$ & $19.7 \%$ & \multicolumn{2}{|c|}{$2.9 \%$} \\
\hline & \multicolumn{7}{|c|}{ 00-03 } \\
\hline & 468 paragraphs & 233 & 28 & 125 & 60 & \multicolumn{2}{|c|}{22} \\
\hline & $\%$ of code combinations & $49.8 \%$ & $6.0 \%$ & $26.7 \%$ & $12.8 \%$ & \multicolumn{2}{|c|}{$4.7 \%$} \\
\hline & \multicolumn{7}{|c|}{ 04-08 } \\
\hline & 67 paragraphs & 23 & 11 & 37 & 6 & \multicolumn{2}{|c|}{0} \\
\hline & $\%$ of code combinations & $34.3 \%$ & $16.4 \%$ & $40.3 \%$ & $9.0 \%$ & \multicolumn{2}{|c|}{$0.0 \%$} \\
\hline Total counts & 936 paragraphs & 389 & 99 & 278 & 136 & \multicolumn{2}{|c|}{34} \\
\hline Period average & $\%$ of code combinations & $41.6 \%$ & $10.6 \%$ & $29.7 \%$ & $14.5 \%$ & \multicolumn{2}{|c|}{$3.6 \%$} \\
\hline
\end{tabular}

supporting codes - PA1, NPM1 and NPG1 codes vs. criticising or challenging codes - PA2, NPM2 and PG2

${ }^{* *}$ number of absolute counts 
Table 5: Main accounting-related keywords used in the UK political debate, 1991-2008

\begin{tabular}{|c|c|c|c|c|c|c|c|c|c|}
\hline \multirow{2}{*}{\begin{tabular}{|l} 
PA \\
Keyword
\end{tabular}} & \multicolumn{2}{|c|}{ 1991-1995 } & \multicolumn{2}{|c|}{ 1996-1999 } & \multicolumn{2}{|c|}{ 2000-2003 } & \multicolumn{2}{|c|}{ 2004-2008 } & \multirow{2}{*}{$\begin{array}{c}\text { Entire period } \\
\%\end{array}$} \\
\hline & Counts & $\%$ & Counts & $\%$ & Counts & $\%$ & Counts & $\%$ & \\
\hline Cash/commitment & 307 & $26.8 \%$ & 1,042 & $18.1 \%$ & 583 & $21.2 \%$ & 2 & $0.6 \%$ & $19.4 \%$ \\
\hline Citizen & 4 & $0.3 \%$ & 10 & $0.2 \%$ & 14 & $0.5 \%$ & 125 & $39.8 \%$ & $1.5 \%$ \\
\hline Expenditure & 306 & $26.7 \%$ & 1,725 & $29.9 \%$ & 694 & $25.2 \%$ & 41 & $13.1 \%$ & $27.7 \%$ \\
\hline Procedures & 48 & $4.2 \%$ & 1,023 & $17.8 \%$ & 164 & $6.0 \%$ & 15 & $4.8 \%$ & $12.5 \%$ \\
\hline Requirement & 135 & $11.8 \%$ & 374 & $6.5 \%$ & 281 & $10.2 \%$ & 12 & $3.8 \%$ & $8.0 \%$ \\
\hline Rules & 31 & $2.7 \%$ & 313 & $5.4 \%$ & 135 & $4.9 \%$ & 17 & $5.4 \%$ & $5.0 \%$ \\
\hline Spending & 125 & $10.9 \%$ & 809 & $14.0 \%$ & 445 & $16.2 \%$ & 50 & $15.9 \%$ & $14.3 \%$ \\
\hline Overall PA word counts & \multicolumn{2}{|c|}{1,147} & \multicolumn{2}{|c|}{5,762} & \multicolumn{2}{|c|}{2,750} & \multicolumn{2}{|c|}{314} & 9,973 \\
\hline NPM & \multicolumn{2}{|c|}{ 1991-1995 } & \multicolumn{2}{|c|}{ 1996-1999 } & \multicolumn{2}{|c|}{$2000-03$} & \multicolumn{2}{|c|}{ 2004-2008 } & \multirow{2}{*}{$\begin{array}{c}\text { Entire period } \\
\%\end{array}$} \\
\hline Keyword & Counts & $\%$ & Counts & $\%$ & Counts & $\%$ & Counts & $\%$ & \\
\hline Audit/Auditing & 170 & $6.8 \%$ & 510 & $7.1 \%$ & 1,485 & $18.7 \%$ & 15 & $1.9 \%$ & $11.9 \%$ \\
\hline Cost & 418 & $16.7 \%$ & 1090 & $15.3 \%$ & 428 & $5.4 \%$ & 42 & $5.4 \%$ & $10.8 \%$ \\
\hline $\begin{array}{l}\text { Independence/independent/autonomo } \\
\text { us }\end{array}$ & 24 & $1.0 \%$ & 159 & $2.2 \%$ & 508 & $6.4 \%$ & 24 & $3.1 \%$ & $3.9 \%$ \\
\hline Objective & 166 & $6.6 \%$ & 426 & $6.0 \%$ & 186 & $2.3 \%$ & 52 & $6.6 \%$ & $3.4 \%$ \\
\hline Performance & 120 & $4.8 \%$ & 225 & $3.2 \%$ & 482 & $6.1 \%$ & 70 & $9.0 \%$ & $4.9 \%$ \\
\hline Process & 91 & $3.6 \%$ & 296 & $4.1 \%$ & 374 & $4.7 \%$ & 78 & $10.0 \%$ & $4.6 \%$ \\
\hline Resources (in RAB terms) & 774 & $30.9 \%$ & 2,552 & $35.8 \%$ & 2,204 & $27.7 \%$ & 97 & $12.4 \%$ & $30.6 \%$ \\
\hline $\begin{array}{l}\text { Managerial responsibility/ } \\
\text { responsibility centre }\end{array}$ & 100 & $4.0 \%$ & 251 & $3.5 \%$ & 286 & $3.6 \%$ & 55 & $7.0 \%$ & $3.8 \%$ \\
\hline Target & 37 & $1.5 \%$ & 134 & $1.9 \%$ & 198 & $2.5 \%$ & 34 & $4.3 \%$ & $2.2 \%$ \\
\hline Overall NPM word counts & \multicolumn{2}{|c|}{2,503} & \multicolumn{2}{|c|}{7,133} & \multicolumn{2}{|c|}{7,949} & \multicolumn{2}{|c|}{782} & 18,367 \\
\hline NPG & \multicolumn{2}{|c|}{ 1991-1995 } & \multicolumn{2}{|c|}{ 1996-1999 } & \multicolumn{2}{|c|}{$2000-2003$} & \multicolumn{2}{|c|}{ 2004-2008 } & Entire period \\
\hline Keyword & Counts & $\%$ & Counts & $\%$ & Counts & $\%$ & Counts & $\%$ & $\%$ \\
\hline External accountability & 30 & $12.1 \%$ & 122 & $16.6 \%$ & 351 & $26.1 \%$ & 50 & $25.3 \%$ & $21.9 \%$ \\
\hline Consolidation/consolidated & 120 & $48.4 \%$ & 375 & $51.0 \%$ & 263 & $19.6 \%$ & 4 & $2.0 \%$ & $30.2 \%$ \\
\hline
\end{tabular}




\begin{tabular}{|c|c|c|c|c|c|c|c|c|c|}
\hline Governance & 0 & $0.0 \%$ & 2 & $0.3 \%$ & 25 & $1.9 \%$ & 69 & $34.8 \%$ & $3.8 \%$ \\
\hline Integration/integrated & 6 & $2.4 \%$ & 10 & $1.4 \%$ & 6 & $0.4 \%$ & 13 & $6.6 \%$ & $1.4 \%$ \\
\hline $\begin{array}{l}\text { Negotiation/ consultation (with } \\
\text { external stakeholders) }\end{array}$ & 83 & $33.5 \%$ & 5 & $0.7 \%$ & 185 & $13.8 \%$ & 5 & $2.5 \%$ & $11.0 \%$ \\
\hline Network & 1 & $0.4 \%$ & 11 & $1.5 \%$ & 5 & $0.4 \%$ & 11 & $5.6 \%$ & $1.1 \%$ \\
\hline Participation/participative & 1 & $0.4 \%$ & 24 & $3.3 \%$ & 35 & $2.6 \%$ & 15 & $7.6 \%$ & $3.0 \%$ \\
\hline Transparency/transparent & 3 & $1.2 \%$ & 123 & $16.7 \%$ & 116 & $8.6 \%$ & 18 & $9.1 \%$ & $10.3 \%$ \\
\hline Overall NPG word counts & \multicolumn{2}{|c|}{248} & \multicolumn{2}{|c|}{736} & & $\Delta$ & \multicolumn{2}{|c|}{198} & 2,525 \\
\hline
\end{tabular}




\section{Appendix 1}

\section{Keywords identification}

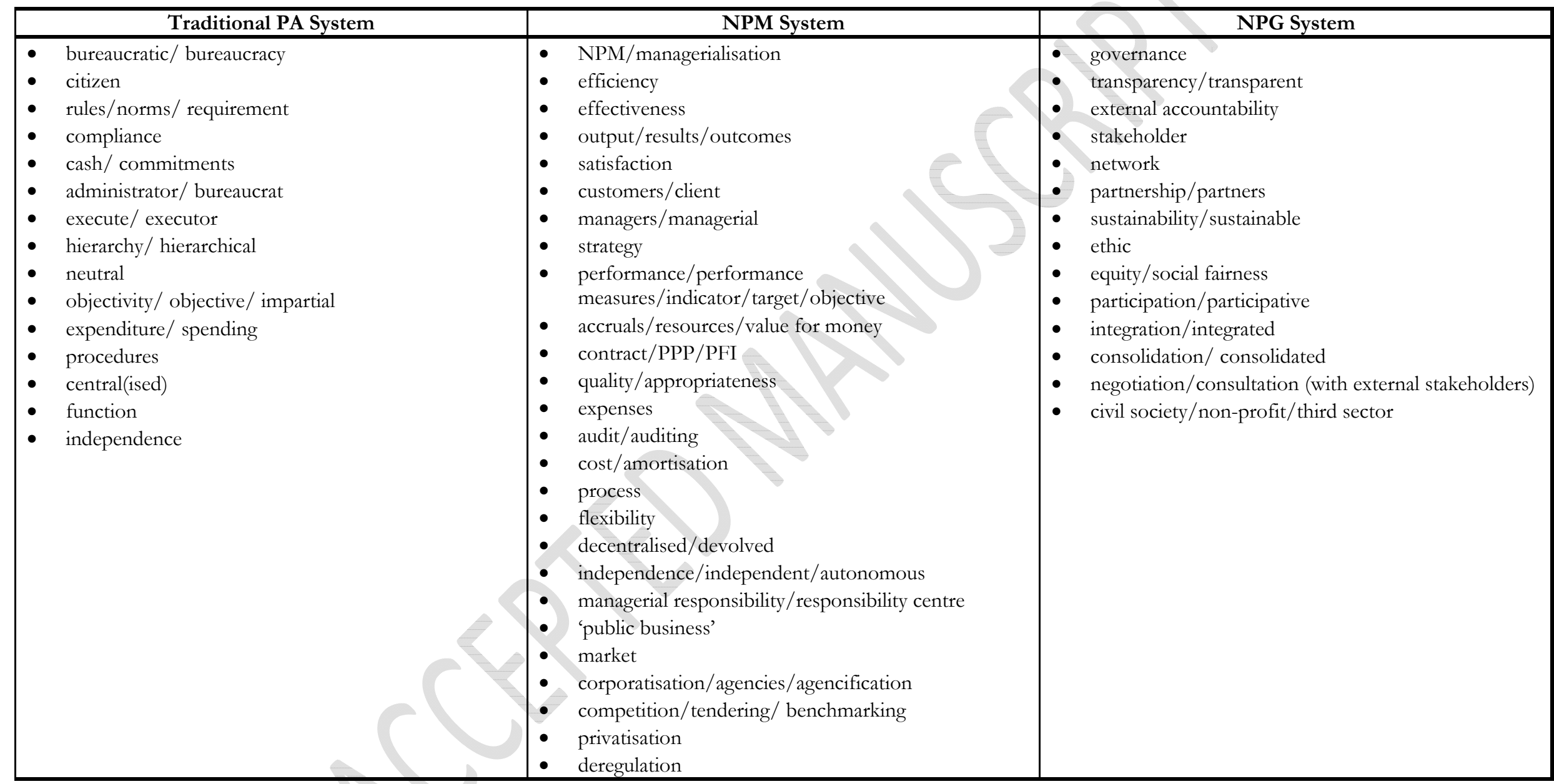

